\title{
Regulatory roles of miRNAs 16, 133a, and 223 on osteoclastic bone destruction caused by breast cancer metastasis
}

\author{
KAZUMICHI KITAYAMA ${ }^{1}$, TERUYA KAWAMOTO ${ }^{1,2}$, YOHEI KAWAKAMI ${ }^{1}$, HITOMI HARA ${ }^{1}$, \\ TOSHIYUKI TAKEMORI $^{1}$, SHUICHI FUJIWARA ${ }^{1}$, SHUNSUKE YAHIRO ${ }^{1}$, TOMOHIRO MIYAMOTO ${ }^{1}$, \\ YUTAKA MIFUNE $^{1}$, YUICHI HOSHINO ${ }^{1}$, KENICHIRO KAKUTANI ${ }^{1}$, TOMOYUKI MATSUMOTO ${ }^{1}$, \\ TAKEHIKO MATSUSHITA ${ }^{1}$, TAKAHIRO NIIKURA ${ }^{1}$, RYOSUKE KURODA ${ }^{1}$ and TOSHIHIRO AKISUE ${ }^{1,3}$ \\ ${ }^{1}$ Department of Orthopaedic Surgery, Kobe University Graduate School of Medicine, Kobe, Hyogo 650-0017; \\ ${ }^{2}$ Division of Orthopaedic Surgery, Kobe University Hospital International Clinical Cancer Research Center, \\ Kobe, Hyogo 650-0047; ${ }^{3}$ Department of Rehabilitation Science, Kobe University \\ Graduate School of Health Science, Kobe, Hyogo 654-0142, Japan
}

Received July 13, 2021; Accepted October 4, 2021

DOI: 10.3892/ijo.2021.5277

\begin{abstract}
Osteolytic bone metastasis leads to skeletal-related events, resulting in a decline in the patient activities and survival; therefore, it is important to understand the mechanism underlying bone metastasis. Recent studies have suggested that microRNAs (miRNAs or miRs) are involved in osteoclast differentiation and/or osteolytic bone metastasis; however, the roles of miRNAs have not been elucidated. In the present study, the roles of miRNAs in bone destruction caused by breast cancer metastasis were investigated in vitro and in vivo. miR-16, miR-133a and miR-223 were transfected into a human breast cancer cell line, MDA-MB-231. The expression of osteolytic factors in conditioned medium (miR-CM) collected from the culture of transfected cells was assessed. To evaluate the effects of miRNAs on osteoclast differentiation and activities, tartrate-resistant acid phosphatase (TRAP) staining and bone resorptive assays were performed in osteoclasts following miR-CM treatment. To create in vivo bone metastasis models for histological and morphometric evaluation, miRNA-transfected MDA-MB-231 cells were transplanted into the proximal tibia of nude mice. Expression of osteolytic factors, including receptor activator for nuclear factor- $\kappa \mathrm{B}$ ligand (RANKL), interleukin (IL)-1 $\beta$, IL-6, parathyroid hormone-related protein (PTHrP), and tumor necrosis factor (TNF), was increased in miR-16-CM, whereas it was decreased in both miR-133a-CM and miR-223-CM. TRAP staining and bone resorptive assays revealed that osteoclast
\end{abstract}

Correspondence to: Dr Teruya Kawamoto, Department of Orthopaedic Surgery, Kobe University Graduate School of Medicine, 7-5-1 Kusunoki-cho, Chuo-ku, Kobe, Hyogo 650-0017, Japan E-mail: trykwmt@med.kobe-u.ac.jp

Key words: bone metastasis, breast cancer, microRNA, microRNA-16, microRNA-133a, microRNA-223, osteoclast function and activities were promoted by miR-16-CM treatment, whereas they were suppressed by miR-133a-CM and miR-223-CM. Consistent with in vitro findings, in vivo experiments revealed that the overexpression of miR-16 increased osteoclast activities and bone destruction in MDA-MB-231 cells, whereas the opposite results were observed in both miR-133a- and miR-223-transfected MDA-MB-231 cells. Our results indicated that miR-16 promoted osteoclast activities and bone destruction caused by breast cancer metastasis in the bone microenvironment, whereas miR-133a and miR-223 suppressed them. These miRNAs could be potential biomarkers and therapeutic targets for breast cancer bone metastasis.

\section{Introduction}

Breast cancer is one of the most common cancers and the leading cause of cancer-related deaths among women worldwide. It is estimated that there were 1.7 million breast cancer cases and 520,000 breast cancer-related deaths in 2012. Breast cancer accounts for $25 \%$ of all cancer cases and for $15 \%$ of all cancer deaths among women (1). In recent years, significant advances in early diagnosis and effective treatments for the disease have been achieved resulting in improved overall survival of breast cancer patients. However, metastasis represents a large obstacle to reduce the mortality rate in breast cancer and remains the primary cause of breast cancer-related mortalities (2). Bone is the most common site for breast cancer metastasis (3). It has been reported that $50-60 \%$ of metastatic breast cancer patients develop bone metastases in the advanced stage of breast cancer (4); 5-6\% of all breast cancer patients exhibit bone metastases at diagnosis (5). Bone metastasis remains incurable and causes skeletal-related events, such as pain, hypercalcemia, pathological fracture, and spinal cord compression, which lead to the poor quality of life and/or activities of the patients (6). It has also been revealed that breast cancer patients with complications due to bone metastasis have shorter median survival time than that of patients without bone complications (7). Thus, understanding 
the mechanism underlying bone metastasis is crucial to treat it in its early stages.

Breast cancer cells themselves are not capable of carrying out the highly specialized function of bone resorption (8). The formation of bony osteolytic lesions by solid tumor metastasis mainly depends on the activation of osteoclasts $(9,10)$. Osteoclastogenesis is regulated by exogenous hormones, cytokines, and various transcriptional factors. It is known that cancer cells are capable of promoting osteoclast differentiation, function, and activities $(8,11)$. Breast cancer cells have been reported to secrete various factors that act on pre-osteoclasts, osteoblasts, and bone stromal cells, which stimulate the differentiation of mature osteoclasts $(11,12)$. Hussein et al reported that the macrophage colony-stimulating factor and the phospholipase $\mathrm{C}-\gamma$ produced by metastatic breast cancer cells could prolong osteoclast survival and block the apoptotic effect of bisphosphonates (13).

MicroRNAs (miRNAs or miRs) are small, non-coding RNAs that regulate gene expression by translational inhibition and degradation of mRNAs $(14,15)$. They have been recognized to play important roles in various biological processes, including cell differentiation, proliferation, apoptosis, and tumorigenesis $(14,15)$. Therefore, miRNAs are considered to have significant clinical potential; for example, they may be used as new therapeutic targets and disease-specific biomarkers (16). Previous studies have also suggested that several miRNAs could play important roles in the progression of breast cancer, and bone metastasis with osteoclast differentiation and/or function $(17,18)$. Ell et al reported that miR-16 levels are higher in the serum of patients with breast cancer bone metastasis than that in healthy donors (17). In addition, in the case of breast cancer with bone metastasis, miR-16 levels were increased in osteoclast differentiation and bone metastasis (18). Conversely, there are several studies that have reported that miR-133a and miR-223 may act as suppressors not only in breast cancer progression but also in bone destruction (14,17-19). It has been reported that miR-133a acts as a tumor suppressor in breast cancer by targeting LIM and SH3 domain protein 1 (LASP1) (19), and that the ectopic expression of miR-133a may inhibit osteoclast differentiation and bone resorption (17). Other studies indicated that miR-223 reduces tumor growth in breast cancer (20), and plays essential roles during osteoclast differentiation $(21,22)$. However, there is no detailed study in which the roles of miRNAs in osteoclastic bone destruction caused by breast cancer bone metastasis have been revealed. Based on this background, it was hypothesized that miR-16, miR-133a and miR-223 could regulate osteoclast differentiation, function, and/or activities in breast cancer bone metastasis, thereby controlling metastatic bone destruction. In the present study, to investigate the roles of these miRNAs in bone destruction caused by breast cancer metastasis, their effects on the expression of osteolytic factors and osteoclast activity were examined in vitro, and on bone destruction in vivo.

\section{Materials and methods}

Cell culture. A human-derived breast cancer cell line, MDA-MB-231 (HTB-26), and a mouse macrophage cell line, RAW264.7 (TIB-71), both obtained from the American Type Culture Collection (ATCC), were used in the present study. The RAW 264.7 cells are known as preosteoclast cells, which readily differentiate into osteoclasts upon exposure to receptor activator for nuclear factor- $\kappa B$ ligand (RANKL) (23). Cells were cultured in Dulbecco's modified Eagle's medium (DMEM) supplemented with 10\% fetal bovine serum (FBS), $100 \mathrm{U} / \mathrm{ml}$ penicillin and $100 \mu \mathrm{g} / \mathrm{ml}$ streptomycin (all from Sigma-Aldrich; Merck KGaA), and maintained in a humidified atmosphere with $5 \% \mathrm{CO}_{2}$ at $37^{\circ} \mathrm{C}$.

Transfection of MDA-MB-231 cells with miRNAs and collection of conditioned medium. MDA-MB-231 cells ( $3 \times 10^{5}$ cells/well) were seeded into 6-well plates on the day before transfection. miRNA-expressing plasmid $(2 \mu \mathrm{g})$ was mixed with $4 \mu \mathrm{l}$ of ViaFect (Promega Corporation) in $200 \mu \mathrm{l}$ of serum-free DMEM, and incubated at room temperature for $15 \mathrm{~min}$ according to the manufacturer's protocol. Then, the mixture was added to the MDA-MB-231 cells and incubated at $37^{\circ} \mathrm{C}$. Following incubation for $24 \mathrm{~h}$, gene transfection efficiency was confirmed by observing GFP expression under a fluorescence microscope (BZ-X700 microscope and BZ-X Viewer; Keyence Corporation) (Fig. S1), and culture medium was collected, filtered through a $0.22-\mu \mathrm{m}$ filter, and used as the miRNA-transfected conditioned medium (miR-16-CM, miR-133a-CM, miR-223-CM and GFP-CM). The miRNA-expressing plasmids used were: pcDNA3-pri-miR-16-1 (cat. no. 51382), pcDNA3.2 mir-1-1 reporter hsa-mir-133a-1 (cat. no. 46676), pcDNA3.2/V5 mmu-mir-223 (cat. no. 26334), and pCDNA3-GFP as the control (cat. no. 74165; all from Addgene, Inc.).

Expression of osteoclast differentiation markers and osteolytic factors in miR-CM. To evaluate the effect of miRNA transfection on the expression of osteoclast differentiation markers and osteolytic factors in MDA-MB-231 cells, total RNA was extracted from miRNA-transfected cells and each CM using the Total Exosome RNA and Protein Isolation Kit (cat. no. 4478545; Invitrogen; Thermo Fisher Scientific, Inc.) according to the manufacturer's protocol. Subsequently, cDNA was synthesized using the MystiCq microRNA cDNA Synthesis Mix (product no. MIRRT-100RXN; Sigma-Aldrich; Merck KGaA) according to the manufacturer's protocol. The expression of each transfected miRNA (miR-16, miR-133a and miR-223) in the cells, and osteoclast differentiation markers and osteolytic factors including RANKL, interleukin (IL)-1 $\beta$, IL-6, parathyroid hormone-related protein (PTHrP), and tumor necrosis factor (TNF), in each miR-CM were examined by reverse transcription-quantitative polymerase chain reaction (RT-qPCR) (Fig. 1).

Effect of miR-CM on osteoclast differentiation in RAW264.7 preosteoclasts in vitro. RAW264.7 cells $\left(8 \times 10^{4}\right.$ cells/well) were seeded in 12-well plates, and after $24 \mathrm{~h}$, the medium was replaced with medium containing $10 \%$ of each miR-CM or $100 \mathrm{ng} / \mathrm{ml}$ of recombinant RANKL (PeproTech EC, Ltd.) as a positive control. Subsequently, 3 days after miR-CM or RANKL treatment, total RNA was isolated from RAW264.7 cells using the RNeasy mini kit (cat. no. 74104; Qiagen, Inc.) and cDNA synthesis was performed using the High-capacity cDNA Transcription kit (cat. no. 4368814; Applied Biosystems; Thermo Fisher Scientific, Inc.), according to the manufacturers' 
Table I. Primer sequences used for reverse transcription-quantitative PCR.

\begin{tabular}{|c|c|}
\hline Primer name & Sequence $\left(5^{\prime} \rightarrow 3^{\prime}\right)$ \\
\hline miR-16 (MIRAP00030) & CCA GUA UUA ACU GUG CUG CUGA \\
\hline miR-133a (MIRAP00155) & UUU GGU CCC CUU CAA CCA GCUG \\
\hline miR-223 (MIRAP00282) & CGU GUA UUU GAC AAG CUG AGUU \\
\hline SNORD43 (MIRCP00004) & $\begin{array}{l}\text { F: CAC AGA UGA UGA ACU UAU UGA CGG GCG GAC AGA } \\
\text { AAC UGU GUG CUG AUU GUC ACG UUC UGA UU }\end{array}$ \\
\hline RANKL & $\begin{array}{ll}\text { F: } & \text { CCC AGA TCA AGG TGG TGT CT } \\
\text { R: } & \text { TGC TGA CCA ATG AGA GCA TC }\end{array}$ \\
\hline IL-1 $\beta$ & $\begin{array}{ll}\text { F: } & \text { GGA CAA GCT GAG GAA GAT GC } \\
\text { R: } & \text { TCG TTA TCC CAT GTG TCG AA }\end{array}$ \\
\hline IL-6 & $\begin{array}{ll}\text { F: } & \text { AAA GAG GCA CTG GCA GAA AA } \\
\text { R: } & \text { TTT CAC CAG GCA AGT CTC CT }\end{array}$ \\
\hline PTHrP & $\begin{array}{ll}\text { F: } & \text { CAT CAG CTC CTC CAT GAC AA } \\
\text { R: } & \text { TCA GCT GTG TGG ATT TCT GC }\end{array}$ \\
\hline TNF & $\begin{array}{ll}\text { F: } & \text { CCT GTG AGG AGG ACG AAC AT } \\
\text { R: } & \text { GGT TGA GGG TGT CTG AAG GA }\end{array}$ \\
\hline NFATc1 & $\begin{array}{ll}\text { F: } & \text { GAA GCA AAG ACT GAC CGG GA } \\
\text { R: } & \text { ATC CTC TGG TTG CGG AAA GG }\end{array}$ \\
\hline OSCAR & $\begin{array}{ll}\text { F: } & \text { GAG CTC TGC CTT TGA TGG TC } \\
\text { R: } & \text { CAA GGA TCC CAG CTT CTC TG }\end{array}$ \\
\hline$\beta 3$-integrin & $\begin{array}{ll}\text { F: } & \text { GAA AGG CCA GTC AGA ACT GC } \\
\text { R: } & \text { TGT GGC CTC CCA GAT TAA AG }\end{array}$ \\
\hline Cathepsin-K & $\begin{array}{ll}\text { F: } & \text { TTC TCC TCT CGT TGG TGC TT } \\
\text { R: } & \text { AAA AAT GCC CTG TTG TGT CC }\end{array}$ \\
\hline TRAP & $\begin{array}{ll}\text { F: } & \text { GAT GAC TTT GCC AGT CAG CA } \\
\text { R: } & \text { AAC TGC TTT TTG AGC CAG GA }\end{array}$ \\
\hline$\beta$-actin & $\begin{array}{ll}\text { F: } & \text { GAT GAG ATT GGC ATG GCT TT } \\
\text { R: } & \text { CAC CTT CAC CGT TCC AGT TT }\end{array}$ \\
\hline
\end{tabular}

RANKL, receptor activator for nuclear factor- $\kappa \mathrm{B}$ ligand; IL, interleukin; PTHrP, parathyroid hormone-related protein; TNF, tumor necrosis factor; NFATc1, nuclear factor of activated T-cells, cytoplasmic 1; OSCAR, osteoclast-associated receptor; TRAP, tartrate-resistant acid phosphatase; F, forward; R, reverse.

protocol. Thereafter, mRNA expression of osteoclast differentiation markers, including nuclear factor of activated T-cells, cytoplasmic 1 (NFATc1), osteoclast-associated receptor (OSCAR), $\beta 3$-integrin, cathepsin-K, and tartrate-resistant acid phosphatase (TRAP), in the cells was assessed by RT-qPCR (Fig. 1).

$R T-q P C R$. RT-qPCR reactions were performed in $20 \mu \mathrm{l}$ reaction mixture volumes using the SYBR-Green master mix reagent (Applied Biosystems; Thermo Fisher Scientific, Inc.) on the ABI Prism 7500 sequence-detection system (Applied Biosystems; Thermo Fisher Scientific, Inc.). qPCR conditions were as follows: one cycle at $95^{\circ} \mathrm{C}$ for $10 \mathrm{~min}$, followed by 40 cycles at $95^{\circ} \mathrm{C}$ for $15 \mathrm{sec}$ and $60^{\circ} \mathrm{C}$ for $1 \mathrm{~min}$. Forward primers for each miRNA (MystiCq microRNA qPCR Assay Primer) were purchased from Sigma-Aldrich; Merck KGaA, and MystiCq Universal PCR Primer (product no. MIRUP; Sigma-Aldrich; Merck KGaA) was used as a reverse primer for the RT-qPCR reactions. Pre-designed primers specific for RANKL, IL-1 $\beta$, IL-6, PTHrP, TNF, NFATc1, OSCAR, $\beta 3$-integrin, cathepsin-K and TRAP were obtained from Invitrogen; Thermo Fisher Scientific, Inc. Primer sequences are listed in Table I. The obtained values were normalized to those for SNORD43 (product no. MIRCP00004; Sigma-Aldrich; Merck KGaA) for miRNA and $\beta$-actin for other genes, and expression levels were quantified using the $2^{-\Delta \Delta \mathrm{Cq}}$ method (24).

In vitro effects of miR-CM on osteoclast activity and function. In vitro effects of miR-CM on osteoclast activity and function in osteoclasts derived from RAW264.7 cells were evaluated (Fig. 1). To generate osteoclasts, RAW264.7 cells were cultured in medium containing $100 \mathrm{ng} / \mathrm{ml}$ of RANKL at $37^{\circ} \mathrm{C}$ for 4 days, and osteoclast formation was confirmed by the presence of TRAP-positive osteoclasts with three or more nuclei under a light microscope. Following confirmation of osteoclast formation, the medium was replaced with 
medium containing $10 \%$ of miR-CM or $100 \mathrm{ng} / \mathrm{ml} \mathrm{RANKL}$ (positive control). TRAP staining was performed after 2 days of miR-CM or RANKL treatment using the standard naphthol AS-BI phosphate post-coupling method (25). Briefly, the cells were fixed in 3.6\% PBS-buffered formalin for $5 \mathrm{~min}$ at room temperature, then incubated at $37^{\circ} \mathrm{C}$ in sodium acetate buffer (pH 5.0) containing $0.01 \%$ naphthol AS-BI phosphate, $0.5 \mathrm{M}$ $\mathrm{L}-(+)$-tartaric acid, and $0.05 \mathrm{M}$ pararosaniline chloride for $20 \mathrm{~min}$, and finally counterstained with hematoxylin at room temperature for $2 \mathrm{~min}$. The number of TRAP-positive multinucleated cells containing three or more nuclei were counted as osteoclasts per three random fields under a light microscope.

Osteoclast function was assessed using bone resorptive assays. RAW264.7 cells $\left(1 \times 10^{4}\right.$ cells/well $)$ were plated on dentin slices (FUJIFILM Wako Pure Chemical Corporation) in 48-well plates. Following confirmation of osteoclast formation after 4 days of $100 \mathrm{ng} / \mathrm{ml}$ RANKL treatment, the medium was replaced with medium containing $10 \%$ of miR-CM or $100 \mathrm{ng} / \mathrm{ml}$ RANKL and refreshed every 2 days. Subsequently, after 4 days of incubation with miR-CM or RANKL at $37^{\circ} \mathrm{C}$, cells were detached from the dentine slices by sonication for 5 min in $0.5 \mathrm{M} \mathrm{NH}_{4} \mathrm{OH}$ (FUJIFILM Wako Pure Chemical Corporation). The slices were stained with $1 \%$ toluidine blue (Muto Pure Chemicals Co., Ltd.) at room temperature for 1 min to visualize resorption pits. The area of the resorption pits was measured in three random fields using a light microscope. All morphometric studies were performed by two examiners blinded to treatment conditions.

Animal models. Female 5-week-old BALB/c nude mice (18-20 g) were purchased from CLEA Japan Inc. Animals were maintained under pathogen-free conditions in accordance with institutional guidelines. All animal procedures were performed in accordance with the Japanese Physiological Society Guidelines for the Care and Use of Laboratory Animals, and the study protocol was approved by the Institutional Animal Care and Use Committee (approval no. P191207) and carried out according to the Kobe University Animal Experimentation Regulations (Kobe, Japan). Animals were fed pathogen-free laboratory chow and were permitted free access to autoclaved water in an air-conditioned room at $25^{\circ} \mathrm{C}$ and $50-60 \%$ humidity with a 12 -h light/dark cycle. To create the in vivo bone metastasis model of breast cancer, 24 mice were randomly divided into four groups with six mice per group: miR-16, miR-133a, miR-223, and GFP (as control). Based on our previous pilot studies, it was determined that six samples would be required in each group to detect differences as calculated using $\mathrm{G}^{*}$ power 3.1 when $\alpha$ was set at 0.05 and power was set at $0.9(26)$. MDA-MB-231 cells transfected with miRNA ( $1 \times 10^{6}$ cells suspended in $10 \mu \mathrm{l}$ PBS) were implanted intramedullary in the proximal epiphysis of the left tibia of 6-week-old mice $(27,28)$. For surgical procedures, mice were anesthetized by intraperitoneal injection of $50 \mathrm{mg} / \mathrm{kg}$ pentobarbital sodium (Kyoritsu Seiyaku) for induction and isoflurane inhalation at a concentration of $2 \%$ for maintenance. At 4 weeks following cell transplantation, all mice were euthanized and their tibiae were removed. Humane endpoints were determined to be when the xenograft tumor reached $>10 \%$ of the animal body weight, the tumor diameter was $>20 \mathrm{~mm}$, body weight loss $>20 \%$ occurred due to tumor growth, and the signs of immobility, the inability to eat, ulceration, infection, or necrosis were observed. All mice reached the study endpoint and were euthanized by cervical dislocation under anesthesia by intraperitoneal injection of $100 \mathrm{mg} / \mathrm{kg}$ pentobarbital sodium. Death was verified by the cessation of the heartbeat of the mice and the dilatation of their pupils.

Micro-computed tomography $(\mu C T)$ analysis. Quantitative analysis of the tibia was performed 4 weeks following cell transplantation using a $\mu$ CT Scanner (R_mCT; Rigaku Mechatronics Co., Ltd.). The bone samples were scanned with parameter settings of tube voltage, $90 \mathrm{kV}$; tube current, $160 \mu \mathrm{A}$; and FOV, $10 \mathrm{~mm}$. For morphometric analyses of the bone samples, a region of interest (ROI) was set $1 \mathrm{~mm}$ below the growth plate with an offset of $200 \mu \mathrm{m}$ from a reference slice. Bone volume/total volume (BV/TV) was assessed using an image analysis system (TRI/3D-BON; RATOC System Engineering).

Hematoxylin and eosin $(H \& E)$ staining and TRAP staining. Tibia samples were fixed in $10 \%$ formalin at room temperature for $48 \mathrm{~h}$, decalcified in $10 \%$ ethylenediaminetetraacetic acid for 2 weeks, and then embedded in paraffin. Paraffin-embedded tibia samples were sliced into $6-\mu \mathrm{m}$ thick sections. After deparaffinization and rehydration, the sections were stained with hematoxylin for $5 \mathrm{~min}$ followed by rinsing in distilled water. Then, the sections were stained with eosin for $2 \mathrm{~min}$ followed by dehydration with graded alcohol and clearing in xylene. All procedures were performed at room temperature. Sections were evaluated using a light microscope to confirm bone destruction and the presence of tumor cells.

For TRAP staining, paraffin-embedded tibia sections were deparaffinized and incubated at $37^{\circ} \mathrm{C}$ in sodium acetate buffer (pH 5.0) containing $0.01 \%$ naphthol AS-BI phosphate and $0.5 \mathrm{M}$ $\mathrm{L}-(+)$-tartaric acid for $20 \mathrm{~min}$. The sections were then incubated in the same buffer containing $0.05 \mathrm{M}$ pararosaniline chloride at $37^{\circ} \mathrm{C}$ for $20 \mathrm{~min}$, followed by washing in distilled water. The sections were counterstained with hematoxylin at room temperature for $30 \mathrm{sec}$. The number of TRAP-positive multinucleated cells containing three or more nuclei were counted as osteoclasts in three random fields under a light microscope.

Immunohistochemical staining. Tibia samples were fixed in $10 \%$ formalin for $48 \mathrm{~h}$, decalcified in $10 \%$ ethylenediaminetetraacetic acid for 2 weeks, then embedded in paraffin and sliced into $6-\mu \mathrm{m}$ thick sections. Paraffin-embedded tibia sections were deparaffinized, and treated with proteinase $\mathrm{K}$ (Dako; Agilent Technologies, Inc.) for $10 \mathrm{~min}$ and $3 \% \mathrm{H}_{2} \mathrm{O}_{2}$ for $5 \mathrm{~min}$ at room temperature followed by overnight incubation at $4^{\circ} \mathrm{C}$ with the following primary antibodies: anti-RANKL rabbit polyclonal antibody (1:200; cat. no. 23408-1-AP), anti-IL-1 $\beta$ rabbit polyclonal antibody (1:200; cat. no. 16806-1-AP), anti-IL-6 mouse monoclonal antibody (1:200; cat. no. 66146-1-Ig), anti-PTHrP rabbit polyclonal antibody (1:200; cat. no. 10817-1-AP), and anti-TNF- $\alpha$ mouse monoclonal antibody (1:200; cat. no. 60291-1-Ig; all from ProteinTech Group, Inc.). Subsequently, the sections were incubated with horseradish peroxidase-conjugated labeled anti-mouse antibody (1:200; cat. no. 424131; Histofine Simplestain Max PO(M); Nichirei Biosciences Inc.) or anti-rabbit antibody (1:200; 


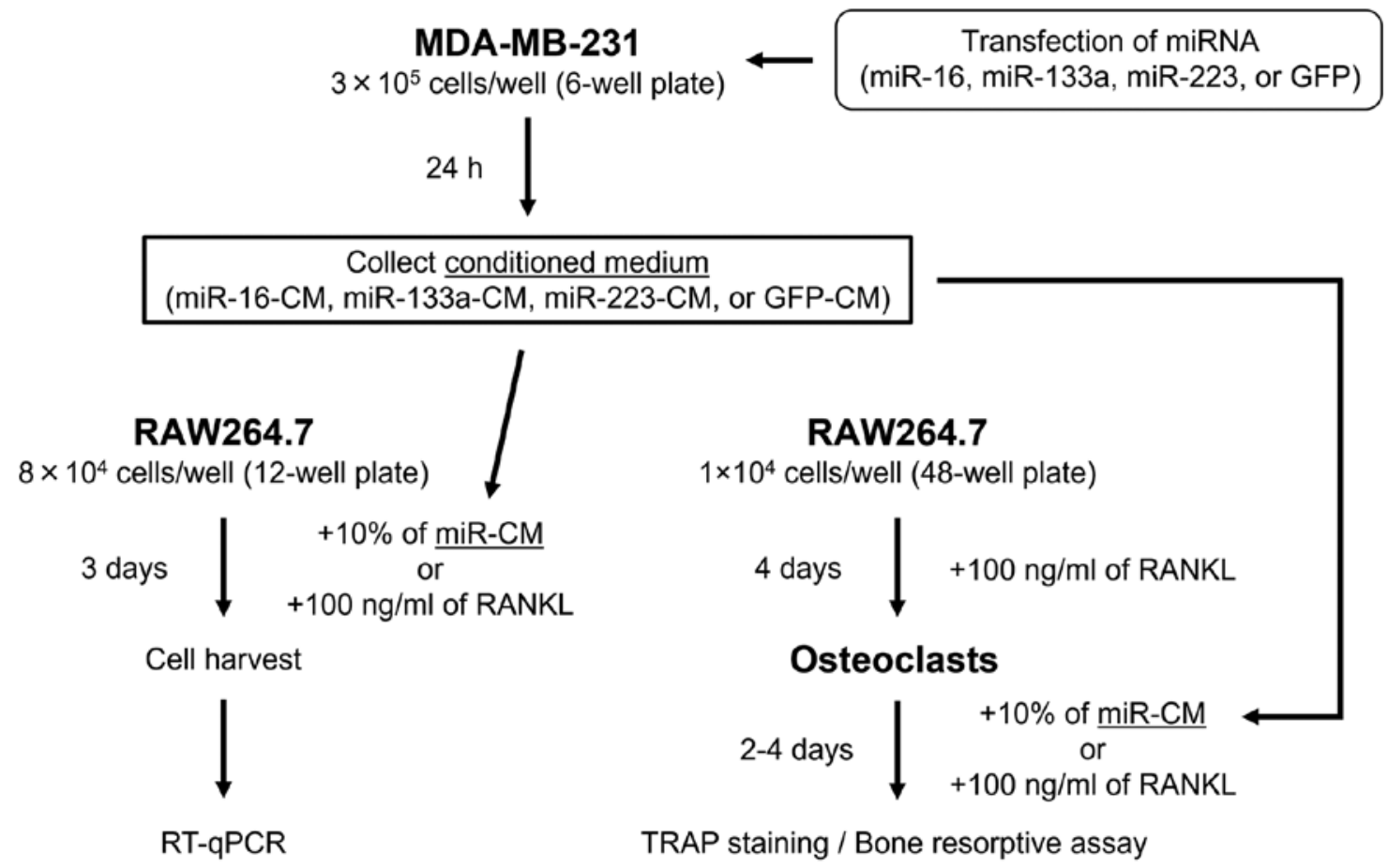

Figure 1. Schematic presentation of in vitro experiments.

cat. no. 424141; Histofine Simplestain Max PO(R); Nichirei Biosciences Inc.) for $30 \mathrm{~min}$ at room temperature, then treated with 3,3'-diaminobenzidine tetrahydrochloride substrate chromogen (cat. no. 415171; Simplestain DAB Solution; Nichirei Biosciences Inc.) for $5 \mathrm{~min}$, and counterstained with hematoxylin for $1 \mathrm{~min}$ at room temperature. Immuno-positive cells were counted in three random fields under a high-power field. All morphometric studies were performed by two examiners blinded to treatment conditions.

Statistical analysis. All experiments were performed independently in triplicate, and statistically analyzed using a software package (GraphPad Prism version 5.02; GraphPad Software, Inc.). Values are presented as the mean \pm standard error of the mean (SEM). Comparisons between two groups were performed using a paired Student's t-test, and comparisons among multiple groups were performed using a one-way analysis of variance (ANOVA) followed by post hoc testing with Tukey's procedure. $\mathrm{P}<0.05$ was considered to indicate a statistically significant difference.

\section{Results}

mRNA expression of osteoclast differentiation and osteolytic factors is increased in miR-16-CM and decreased in miR-133a-CM and miR-223-CM. RT-qPCR analyses revealed that the expression level of miR-16, miR-133a, or miR-223 was significantly increased in the transfected MDA-MB-231 cells $(\mathrm{P}<0.05)$ (Fig. 2A). To examine the effect of miRNA transfection on bone destruction, the expression of osteoclast differentiation markers and osteolytic factors (RANKL, IL-1 $\beta, I L-6, P T H r P$, and $T N F$ ) in the CM of miRNA-transfected MDA-MB-231 cells was evaluated by RT-qPCR analysis. The mRNA expression of $R A N K L, I L-1 \beta, P T H r P$, and $T N F$ was significantly increased in
miR-16-CM compared with that in GFP-CM (P<0.05) (Fig. 2B). The mRNA expression of these genes was significantly decreased in miR-133a-CM $(\mathrm{P}<0.05)$ compared with that in GFP-CM. The expression was also decreased in miR-223-CM, and the decrease in $R A N K L, I L-6$, and $P T H r P$ was significant compared with that in GFP-CM $(\mathrm{P}<0.05)$ (Fig. 2B).

mRNA expression of osteoclast differentiation markers in RAW264.7 pre-osteoclasts is increased by miR-16-CM treatment, but decreased by both miR-133a-CM and miR-223-CM treatments. Toinvestigate the effects of miR-CMon the osteoclast differentiation process, the expression of osteoclast differentiation markers was evaluated in miR-CM-treated RAW264.7 cells. The mRNA expression levels of NFATc1, OSCAR, $\beta 3$-integrin, and cathepsin-K were significantly increased by miR-16-CM treatment compared with that in the control $(\mathrm{P}<0.05)$ (Fig. 2C). The expression of $\beta 3$-integrin, cathepsin-K, and TRAP in miR-133a-CM treated-cells, and that of $O S C A R$, $\beta 3$-integrin, cathepsin-K, and TRAP in miR-223-CM-treated cells was significantly decreased compared with the respective levels in the control $(\mathrm{P}<0.05)$ (Fig. 2C).

Osteoclast formation and activities are promoted by miR-16-CM treatment, but suppressed by both miR-133a-CM and miR-223-CM treatments. The effect of miR-CM treatment on osteoclast formation was evaluated by TRAP staining of miR-CM-treated osteoclasts. The number of TRAP-positive multinucleated osteoclasts was significantly higher in miR-16-CM-treated cells, but lower in both miR-133a-CMand miR-223-CM-treated cells, compared with that of control cells $(\mathrm{P}<0.05)$ (Fig. 3A and $\mathrm{B})$.

Considering that bone resorption is a characteristic feature of osteoclasts, the effect of miR-CM treatment on osteoclastic resorptive function in dentin slices was evaluated. Significantly 
A

A $\quad m i R-16$

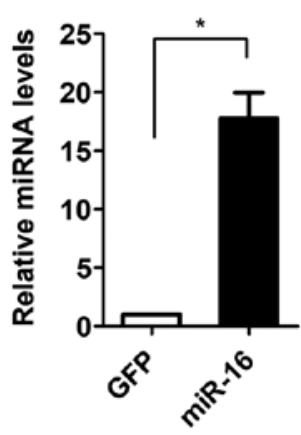

B

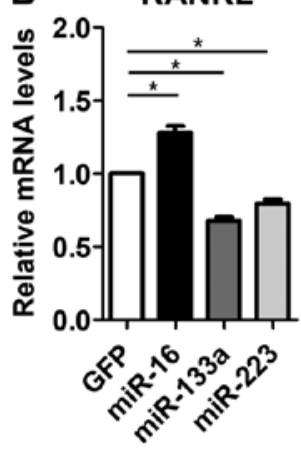

C

NFATc1

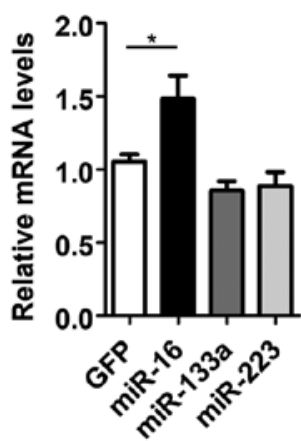

miR-133a

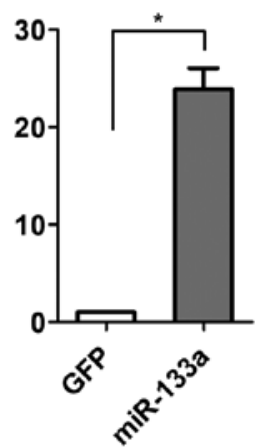

IL-1 $\beta$

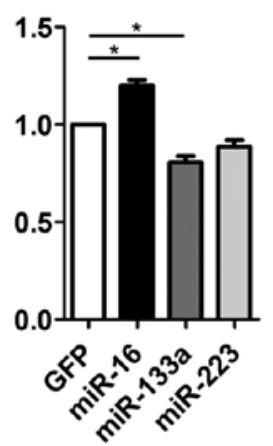

OSCAR

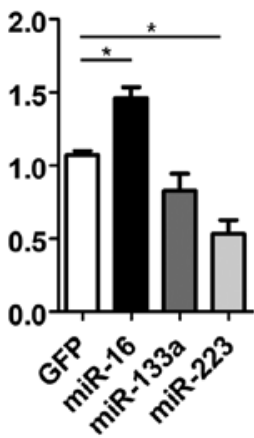

miR-223

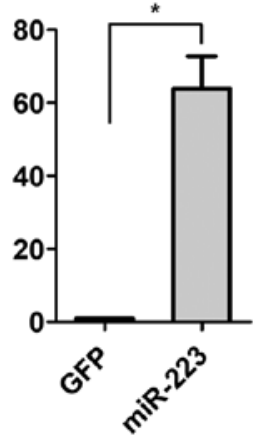

TNF

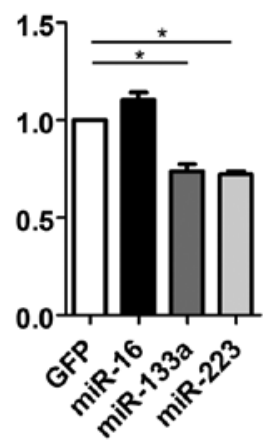

$\beta 3$-integrin

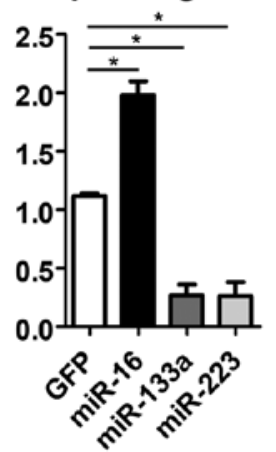

Cathepsin-K

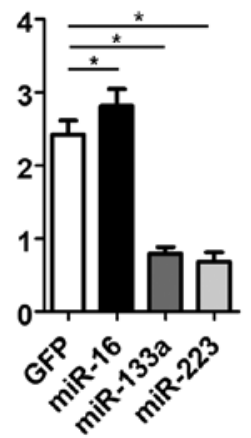

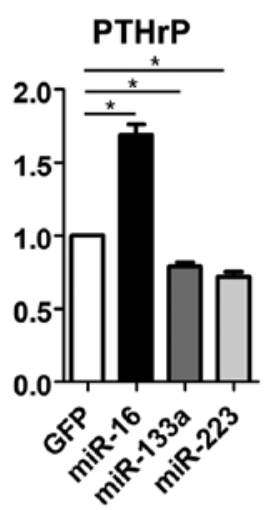

TRAP

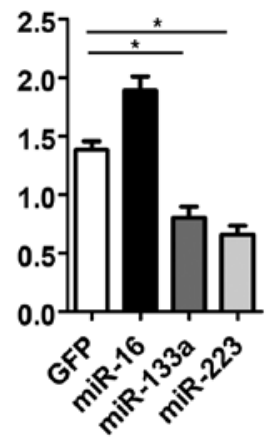

Figure 2. Transfection of miR-16, miR-133a and miR-223 in MDA-MB-231 cells and gene expression in the conditioned media of miRNA-transfected cells (miR-CM). (A) RT-qPCR analyses of the expression levels of miR-16, miR-133a or miR-223 in the cells of each miRNA-transfected group. (B) RT-qPCR analyses for mRNA expression of osteoclast differentiation and osteolytic factors in miR-CM. (C) RT-qPCR analyses of mRNA expression of osteoclast differentiation markers in RAW264.7 cells treated with miR-CM. ${ }^{*} \mathrm{P}<0.05$. miR, microRNA; CM, conditioned medium; RT-qPCR, reverse transcription-quantitative PCR; RANKL, receptor activator for nuclear factor- $\kappa$ B ligand; NFATc1, nuclear factor of activated T-cells cytoplasmic 1; OSCAR, osteoclast-associated receptor; TRAP, tartrate-resistant acid phosphatase; IL, interleukin; PTHrP, parathyroid hormone-related protein; TNF, tumor necrosis factor.

more resorption pits on dentin slices were observed in miR-16-CM-treated osteoclasts, whereas the pits were lesser in miR-133a- or miR-223-treated osteoclasts compared with those in the control (Fig. 3C). The area of resorption pits in miR-16-CM-treated osteoclasts was as large as that in the RANKL-treated osteoclasts. In contrast, in both miR-133a- and miR-223-treated osteoclasts, the area of pits was significantly smaller than that in the control $(\mathrm{P}<0.05)$ (Fig. 3D).

Bone destruction by breast cancer cells is enhanced by miR-16 transfection, but suppressed by either miR-133a or miR-223 transfection along with osteoclast activities. To evaluate the effects of each miRNA on osteoclast formation and bone destruction at the site of bone metastasis, miRNA-transfected
MDA-MB-231 cells were transplanted into the tibiae of nude mice, and histological and morphometric evaluation were performed. $\mu \mathrm{CT}$ analyses revealed that the bone volume of the tibia in the miR-16 group was significantly lower with enhanced bone destruction compared with that in the control group, whereas the bone volume in both the miR-133a and miR-223 groups was significantly higher compared with that in the control group $(\mathrm{P}<0.05)$ (Fig. 4A-C). Consistent with these findings, $H \& E$ staining of the tibia revealed that a larger area of breast cancer cells was observed with normal bone marrow destruction in the miR-16 group, whereas the same area was smaller with less bone destruction in both the miR-133a and miR-223 groups compared with that in the control (Fig. 4D). Additionally, TRAP staining revealed that the number of 

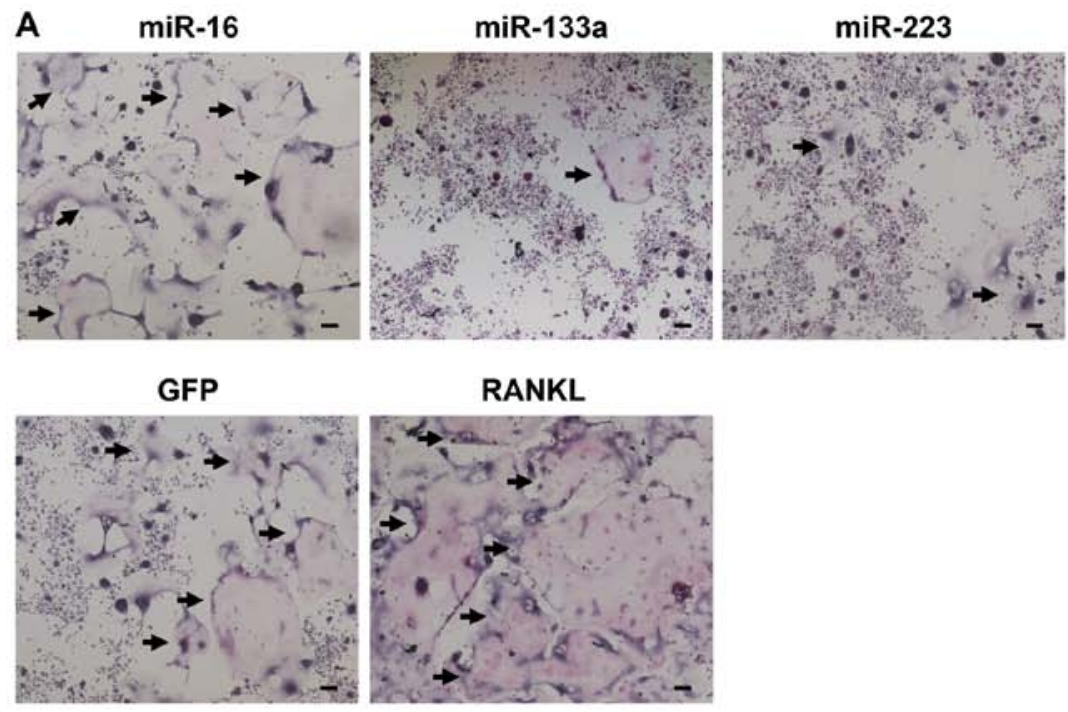

C
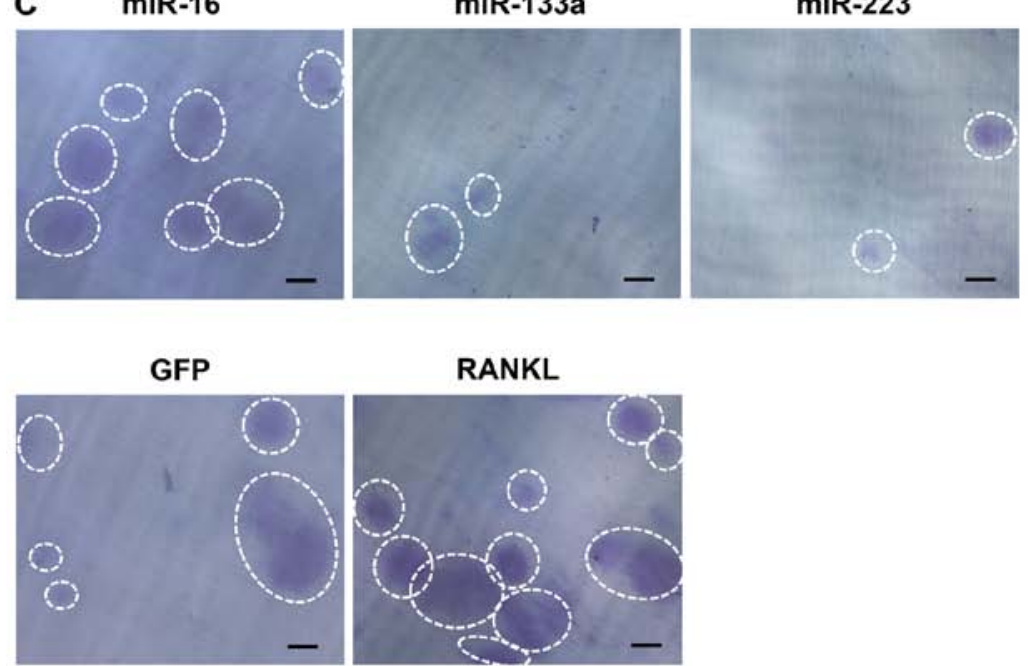

B

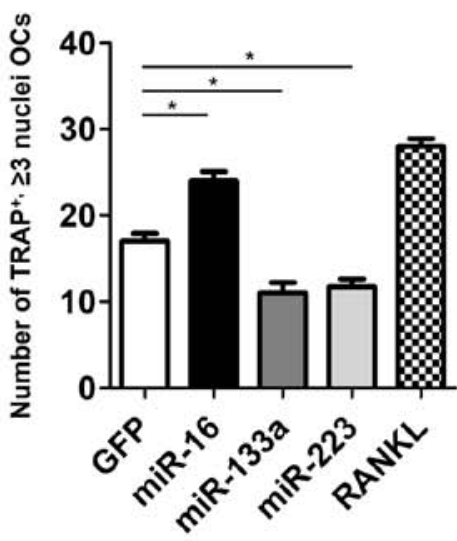

D

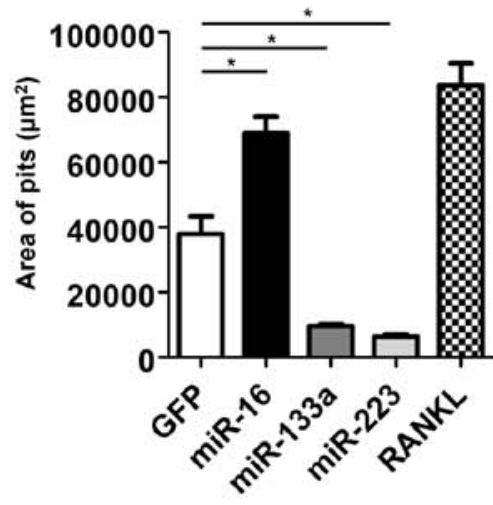

Figure 3. Activity and function of osteoclasts treated with miR-CM in vitro. (A) TRAP staining of osteoclasts treated with each miR-CM (10\%) or $100 \mathrm{ng} / \mathrm{ml}$ RANKL for 2 days. Arrows indicate TRAP-positive osteoclasts. (B) The number of TRAP-positive multinucleated osteoclasts containing three or more nuclei. (C) Resorption pits on dentin slices by osteoclasts treated with each miR-CM (10\%) or $100 \mathrm{ng} / \mathrm{ml} \mathrm{RANKL}$ for 4 days. The area surrounded by the white dotted lines indicates resorption pits. (D) The area of resorption pits measured using the BZ-X700 microscope and BZ-X viewer. Scale bar, $100 \mu \mathrm{m}$. "P $<0.05$. miR, microRNA; CM, conditioned medium; TRAP, tartrate-resistant acid phosphatase; RANKL, receptor activator for nuclear factor- $\mathrm{kB}$ ligand; OC, osteoclast.

TRAP-positive multinucleated osteoclasts was significantly increased in the miR-16 group, but significantly decreased in both miR-133a and miR-223 groups compared with that in the control group $(\mathrm{P}<0.05)$ (Fig. 4E and F). Immunohistochemical staining for osteoclast differentiation markers and osteolytic factors, such as RANKL,IL-1 $\beta$, IL-6, TNF and PTHrP, revealed that the number of immunopositive cells was significantly increased in the miR-16 group, but significantly decreased in both the miR-133a and miR-223 groups compared with that in the control group $(\mathrm{P}<0.05)$ (Fig. 5A and $\mathrm{B})$.

\section{Discussion}

In the present study, the roles of miR-16, miR-133a, and miR-223 on osteoclastic bone destruction by breast cancer metastasis were investigated using the MDA-MB-231 breast cancer cell line in vitro and breast cancer bone metastasis mouse model in vivo. It was demonstrated that the expression of osteolytic factors, such as RANKL, IL-1 $\beta$, IL- 6 , PTHrP and TNF, was enhanced in the culture medium of breast cancer cells that were transfected with miR-16, but decreased in that of cells transfected with miR-133a or 223. In RAW264.7 preosteoclasts, the stimulation of osteoclast differentiation and function by the breast cancer culture medium was promoted by miR-16 overexpression, but was suppressed by miR-133a or miR-223 overexpression. These findings indicated that osteolytic factors derived from breast cancer cells stimulated the osteoclast differentiation and function, and that the effects could be regulated positively by miR-16, but negatively by miR-133a or miR-223 . Consistent with these in vitro results, in vivo experiments using a breast cancer bone metastasis animal model demonstrated that miR-16 enhanced bone destruction with increased osteoclast activities; by contrast, miR-133a and miR-223 prevented the destruction with decreased activities.

Bone lesions by cancer metastasis are caused as a result of an imbalance between bone formation and bone resorption in the bone microenvironment $(10,29,30)$. Both osteolytic and osteoblastic lesions could be caused by cancer bone 
A
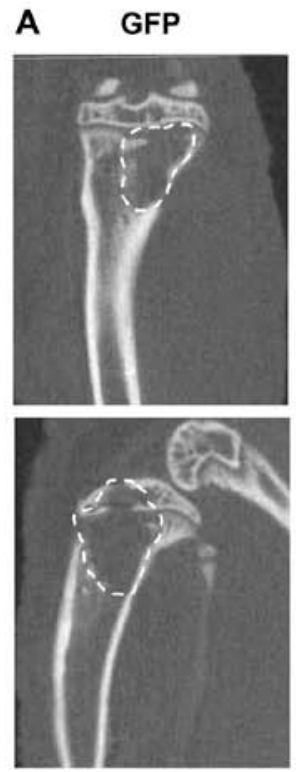

miR-16
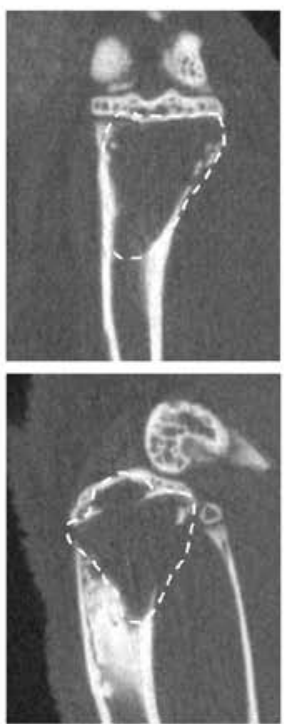

miR-133a
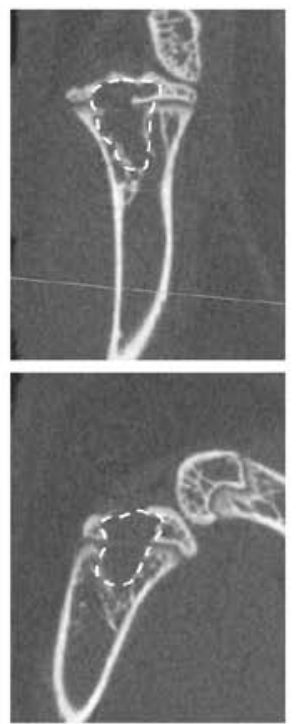

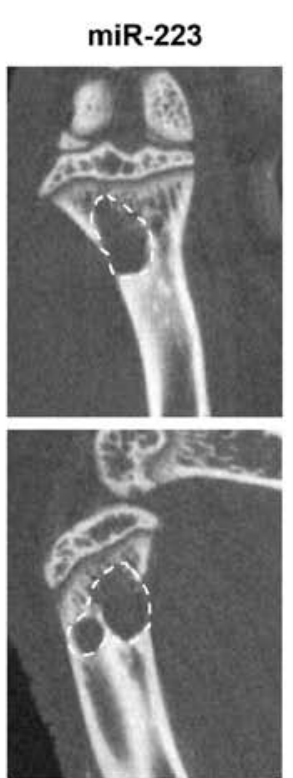

B

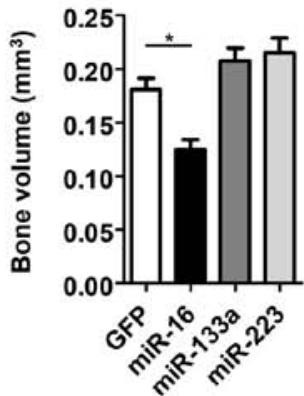

C

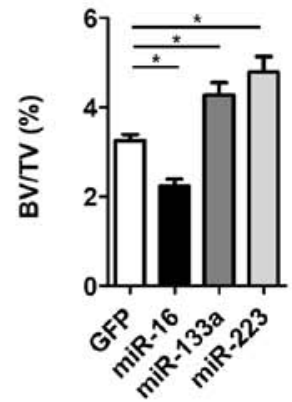

D

GFP

miR-16

miR-133a

miR-223
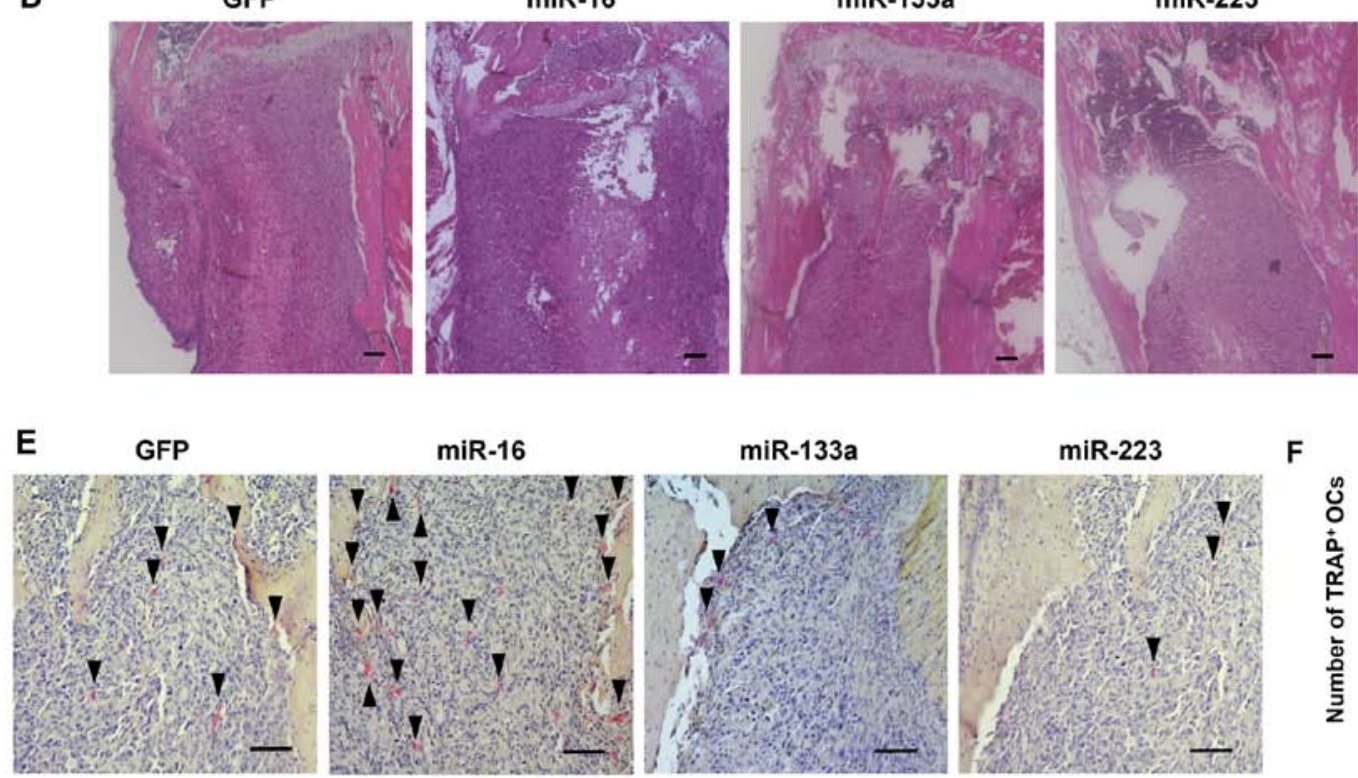

F

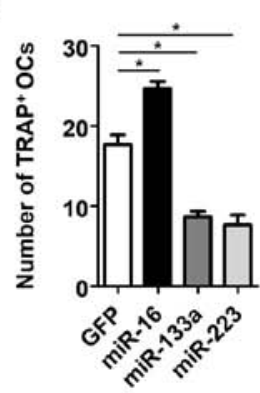

Figure 4. Effects of miRNA on bone destruction and osteoclast activity in vivo. (A) $\mu \mathrm{CT}$ images of proximal tibiae of mice following 4 weeks of cell transplantation. The area surrounded by the white dotted lines indicates the bone resorption area. (B) Bone volume and (C) bone volume/total volume assessed using an image analysis system, TRI/3D-BON. (D) Hematoxylin and eosin and (E) TRAP staining of proximal tibiae of mice following 4 weeks of cell transplantation. Arrow heads indicate TRAP-positive osteoclasts. (F) The number of TRAP-positive multinucleated osteoclasts. Scale bar, $100 \mu \mathrm{m}$. "P<0.05. miR, microRNA; $\mathrm{BV} / \mathrm{TV}$, bone volume/total volume; OC, osteoclast; TRAP, tartrate-resistant acid phosphatase.

metastases (31), and the majority of the lesions caused by breast cancer metastasis have been reported as osteolytic lesions due to the stimulation of osteoclast activities $(32,33)$. Breast cancer cells themselves are unable to perform bone resorption but may stimulate the bone resorptive activity of osteoclasts by secreting RANKL $(8,9)$. Breast cancer cells also secrete factors that promote RANKL production in osteoblasts, immune cells, and bone stromal cells $(8,11,12)$, such as PTHrP, one of the most common tumor-derived factors $(34,35)$. In addition, it has been reported that breast cancer cells could secrete or induce bone stromal cells to release other factors enhancing osteoclast differentiation and bone resorption, such as IL-1 $\beta$,
IL-6, IL-8, IL-11, and TNF (11,36-39). In addition, it has been reported that the conditioned medium of breast cancer cells could prolong the survival of osteoclasts, which die primarily by apoptosis within several days of formation (13). Our findings in the present study support the previous studies, and indicate that breast cancer cell-derived factors, such as RANKL, IL-1 $\beta$, IL-6, PTHrP, and TNF, promote bone resorption by affecting osteoclast differentiation and activity.

miRNAs have been recognized to be important in the regulation of various biological processes of cancer cells $(40,41)$, and several miRNAs, such as miR-16, miR-133a, and miR-223, have been reported to be involved in the progression of breast 

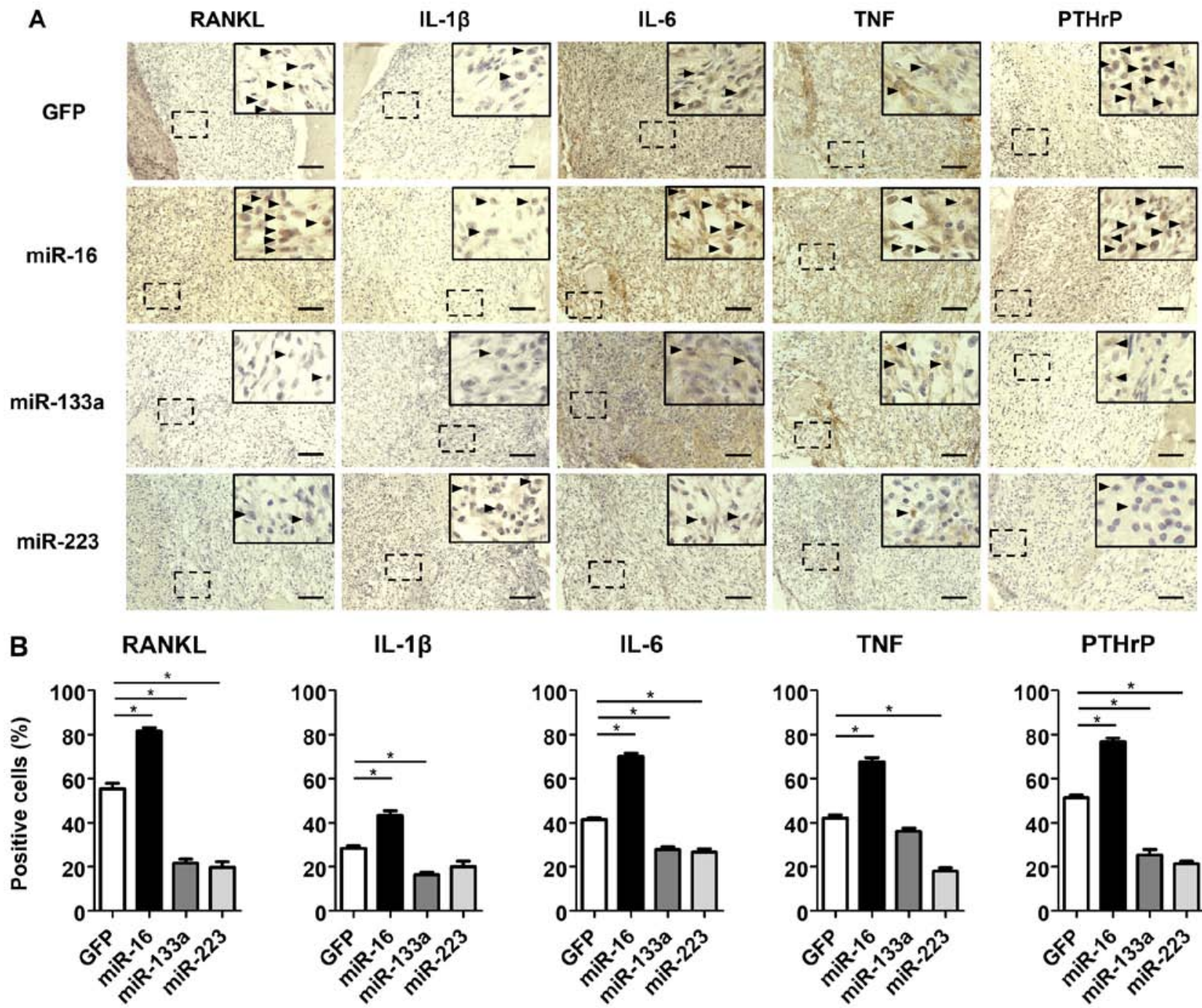

IL-1 $\beta$

IL-6

TNF

PTHrP
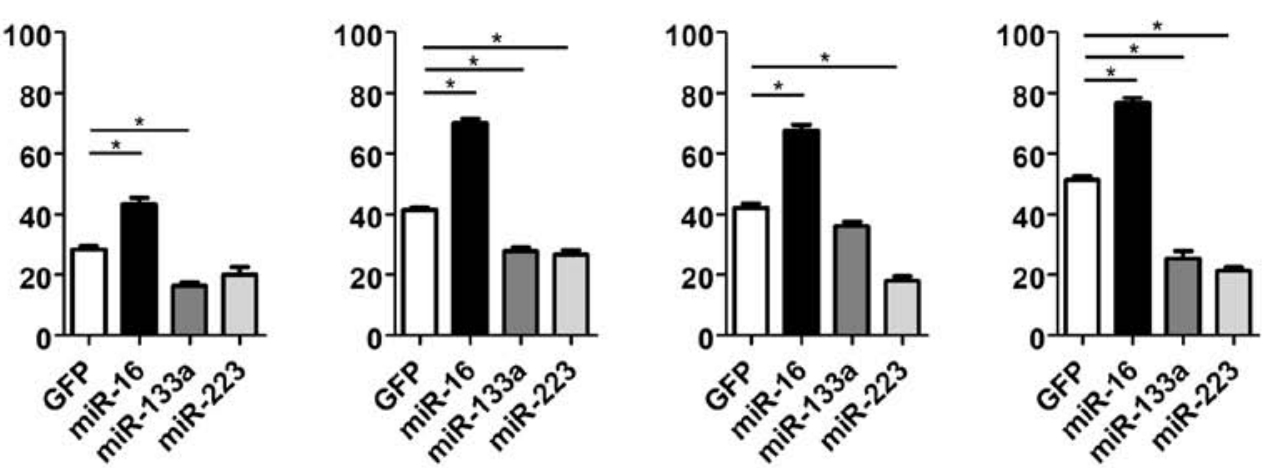

Figure 5. Effects of miRNA on the expression of osteoclast differentiation markers and osteolytic factors in vivo. (A) Immunohistochemical staining for RANKL, IL-1 $\beta$, IL-6, TNF and PTHrP of proximal tibiae of mice following 4 weeks of cell transplantation. Right upper panels in each image indicate high magnification image. Arrow heads indicate immunopositive cells. (B) The number of cells immunopositive for RANKL, IL-1 $\beta$, IL-6, TNF, and PTHrP. Scale bar, $100 \mu \mathrm{m} .{ }^{*} \mathrm{P}<0.05$. miR, microRNA; RANKL, receptor activator for nuclear factor- $\kappa \mathrm{B}$ ligand; IL, interleukin; PTHrP, parathyroid hormone-related protein; TNF, tumor necrosis factor.

cancer, bone metastasis, and osteoclast differentiation or function (14,17-29). Previous studies have suggested that miR-16 could be a promoter of breast cancer bone metastasis $(17,18,42)$. Elevated expression of miR-16 was reported in clinical samples of bone lesions of breast cancer metastasis, compared with that in primary tumor samples (17). Microarray analysis of RAW264.7 preosteoclast cells treated with the culture medium of a highly metastatic breast cancer cell line revealed a significant upregulation of miR-16 (17). In addition, miR-16 upregulation has also been reported in osteoclast differentiation associated with cancer bone metastasis $(18,42)$. By contrast, miR-133a and miR-223 have been widely reported as tumor suppressors in various cancers including breast cancer (43). The downregulation of miR-133a was reported in both breast cancer tissues and cell lines, wherein miR-133a inhibited proliferation, migration, and invasion of breast cancer cells by suppressing LASP1 (19). Both in vitro and in vivo experiments revealed negative regulation by miR-133a on breast cancer metastasis via targeting mastermind-like transcriptional coactivator 1 (44). Ell et al also reported that miR-133a inhibited osteoclast differentiation and reduced osteoclast activities (17). In the case of miR-223, Fabris et al reported that the overexpression of miR-223 could prevent the recurrence of breast cancer by mediating the epidermal growth factor signaling pathway (45). Other studies revealed that miR-223 inhibited the invasion and migration of breast cancer cells, and promoted cell apoptosis by suppressing the expression of epithelial cell transforming sequence 2 oncogene (46), and that miR-223 overexpression in RAW264.7 osteoclast precursors inhibited osteoclast formation in vitro (21). Our results are consistent with previous studies $(17-19,21,42,44)$, indicating that miR-16 positively affects bone metastasis and osteoclast activity in breast cancer, whereas miR-133a and miR-223 regulate them negatively. In the present study, the effect of the miRNAs on the bone resorptive ability of osteoclasts was additionally evaluated using dentin slices in vitro and the same effects were examined in the bone microenvironment using a bone metastasis model in vivo. The majority of the previous studies have assessed osteoclast function only by TRAP staining in vitro, and there are few studies that have evaluated 
the effect of the miRNAs on the actual bone resorptive ability of osteoclasts using dentin slices $(3,21)$. Several miRNAs have been proposed as diagnostic or predictive biomarkers for breast cancer, but none have been validated for practical use in a clinical setting $(47,48)$. In recent years, various studies on targeting miRNAs for therapeutic purposes have been conducted, and it has been demonstrated that miRNAs perform several functions. For example, miR-133a not only acts as a tumor suppressor, but is also involved in muscle development or function, and cardiac remodeling $(49,50)$. Similarly, miR-223 is known to be engaged in the regulation of immune responses in respiratory and liver diseases $(51,52)$. However, the functions of miRNAs have not been fully elucidated $(17,19)$. Therefore, it is important to recognize that miRNA targeting for therapeutic purposes may have unexpected effects on gene expression and/or cause untoward side effects.

There are several limitations to the present study. Firstly, the effects of miRNAs on osteoblasts or stromal cells have not been investigated. As previously reported, bone resorption should be orchestrated by the interaction of various factors from not only osteoclasts or tumor cells but also osteoblasts or stromal cells $(8,11)$. Secondly, the present study was conducted only in the bone microenvironment. Cancer bone metastasis involves multiple processes, including cancer cell dissemination from the primary site and invasion into the vascular system, circulation and adhesion to the target site, and invasion and colonization in the bone microenvironment $(53,54)$. Thirdly, it has been revealed that the miRNAs could affect osteoclast activity and bone destruction using MDA-MB-231 human breast cancer cells; however, only one cell line was used in the present study. Last, only three miRNAs were employed and other miRNAs and/or their interactions were not examined. Therefore, further investigations are required to clarify the effects of miRNAs on breast cancer bone metastasis.

In conclusion, it was demonstrated that miR-16 may enhance bone destruction caused by breast cancer bone metastasis by promoting osteoclast function via increased expression of osteoclast differentiation markers and osteolytic factors, whereas miR-133a and miR-223 may suppress this process. Although further studies are required to further elucidate the effect of miRNAs on cancer bone metastasis, the three miRNAs could serve as biomarkers and/or therapeutic targets for metastatic bone destruction in breast cancer.

\section{Acknowledgements}

The authors would like to thank Ms Minako Nagata, Ms Maya Yasuda and Ms Kyoko Tanaka (Department of Orthopaedic Surgery, Kobe University Graduate School of Medicine, Kobe, Japan) for their expert technical assistance.

\section{Funding}

This work was supported by JSPS KAKENHI (grant no. 20K16357).

\section{Availability of data and materials}

The datasets used and/or analyzed during the current study are available from the corresponding author on reasonable request.

\section{Authors' contributions}

KKi and YK wrote the manuscript, collected and/or assembled data and performed data analysis and interpretation. HH, TT, TMi, YM, YH, KKa, TMatsum, TMatsus and TN collected and/or assembled data. KKi, TK and YK confirmed the authenticity of all the raw data. SF and SY performed data analysis and interpretation. TK, RK and TA conceived/designed, collected and/or assembled data, performed data analysis and interpretation, and gave final approval of the manuscript. All authors read and approved the final manuscript.

\section{Ethics approval and consent to participate}

All animal procedures were performed in accordance with the Japanese Physiological Society Guidelines for the Care and Use of Laboratory Animals. This study was approved by the Institutional Animal Care and Use Committee (approval no. P191207) and carried out according to the Kobe University Animal Experimentation Regulations (Kobe, Japan).

\section{Patient consent for publication}

Not applicable.

\section{Competing interests}

The authors declare that they have no competing interests.

\section{References}

1. Torre LA, Bray F, Siegel RL, Ferlay J, Lortet-Tieulent J and Jemal A: Global cancer statistics, 2012. CA Cancer J Clin 65: 87-108, 2015.

2. Li Z and Kang Y: Emerging therapeutic targets in metastatic progression: A focus on breast cancer. Pharmacol Ther 161: 79-96, 2016.

3. Cai WL, Huang WD, Li B, Chen TR, Li ZX, Zhao CL, Li HY, Wu YM, Yan WJ and Xiao JR: microRNA-124 inhibits bone metastasis of breast cancer by repressing Interleukin-11. Mol Cancer 17: 9, 2018.

4. Coleman RE: Bisphosphonates: Clinical experience. Oncologist 9 (Suppl 4): 14-27, 2004.

5. D'Oronzo S, Gregory W, Nicholson S, Chong YK, Brown J and Coleman R: Natural history of stage II/III breast cancer, bone metastasis and the impact of adjuvant zoledronate on distribution of recurrences. J Bone Oncol 28: 100367, 2021.

6. Tanaka R, Yonemori K, Hirakawa A, Kinoshita F, Takahashi N, Hashimoto J, Kodaira M, Yamamoto H, Yunokawa M, Shimizu C, et al: Risk factors for developing skeletal-related events in breast cancer patients with bone metastases undergoing treatment with bone-modifying agents. Oncologist 21: 508-513, 2016.

7. Coleman RE and Rubens RD: The clinical course of bone metastases from breast cancer. Br J Cancer 55: 61-66, 1987.

8. Lu X and Kang Y: Organotropism of breast cancer metastasis. J Mammary Gland Biol Neoplasia 12: 153-162, 2007.

9. Taube T, Elomaa I, Blomqvist C, Beneton MN and Kanis JA: Histomorphometric evidence for osteoclast-mediated bone resorption in metastatic breast cancer. Bone 15: 161-166, 1994.

10. Weidle UH, Birzele F, Kollmorgen G and Rüger R: Molecular mechanisms of bone metastasis. Cancer Genomics Proteomics 13: 1-12, 2016.

11. Siclari VA, Guise TA and Chirgwin JM: Molecular interactions between breast cancer cells and the bone microenvironment drive skeletal metastases. Cancer Metastasis Rev 25: 621-633, 2006.

12. Sutherland A, Forsyth A, Cong Y, Grant L, Juan TH, Lee JK, Klimowicz A, Petrillo SK, Hu J, Chan A, et al: The role of prolactin in bone metastasis and breast cancer cell-mediated osteoclast differentiation. J Natl Cancer Inst 108: 108, 2015. 
13. Hussein O, Tiedemann K and Komarova SV: Breast cancer cells inhibit spontaneous and bisphosphonate-induced osteoclast apoptosis. Bone 48: 202-211, 2011.

14. Bartel DP: MicroRNAs: Genomics, biogenesis, mechanism, and function. Cell 116: 281-297, 2004.

15. Bartel DP: MicroRNAs: Target recognition and regulatory functions. Cell 136: 215-233, 2009

16. Browne G, Taipaleenmäki H, Stein GS, Stein JL and Lian JB MicroRNAs in the control of metastatic bone disease. Trends Endocrinol Metab 25: 320-327, 2014.

17. Ell B, Mercatali L, Ibrahim T, Campbell N, Schwarzenbach H, Pantel K, Amadori D and Kang Y: Tumor-induced osteoclast miRNA changes as regulators and biomarkers of osteolytic bone metastasis. Cancer Cell 24: 542-556, 2013.

18. Usmani A, Shoro AA, Shirazi B, Memon Z and Hussain M MiR-16: A novel hereditary marker in breast cancer and their offspring. J Pak Med Assoc 67: 446-450, 2017.

19. Sui Y, Zhang X, Yang H, Wei W and Wang M: MicroRNA-133a acts as a tumour suppressor in breast cancer through targeting LASP1. Oncol Rep 39: 473-482, 2018.

20. Zhang L, Li H, Zang Y and Wang F: NLRP3 inflammasome inactivation driven by miR $2233 \mathrm{p}$ reduces tumor growth and increases anticancer immunity in breast cancer. Mol Med Rep 19: 2180-2188, 2019

21. Sugatani T and Hruska KA: MicroRNA-223 is a key factor in osteoclast differentiation. J Cell Biochem 101: 996-999, 2007.

22. Sugatani $T$ and Hruska KA: Impaired micro-RNA pathways diminish osteoclast differentiation and function. J Biol Chem 284 4667-4678, 2009.

23. Xu XY, Guo C, Yan YX, Guo Y, Li RX, Song M and Zhang XZ: Differential effects of mechanical strain on osteoclastogenesis and osteoclast-related gene expression in RAW264.7 cells. Mol Med Rep 6: 409-415, 2012.

24. Livak KJ and Schmittgen TD: Analysis of relative gene expression data using real-time quantitative PCR and the 2(-Delta Delta C(T)) method. Methods 25: 402-408, 2001.

25. Modderman WE, Tuinenburg-Bol Raap AC and Nijweide PJ: Tartrate-resistant acid phosphatase is not an exclusive marker for mouse osteoclasts in cell culture. Bone 12: 81-87, 1991.

26. Faul F, Erdfelder E, Lang AG and Buchner A: G*Power 3 : A flexible statistical power analysis program for the social, behavioral, and biomedical sciences. Behav Res Methods 39: 175-191, 2007.

27. Okada Y, Ueno H, Katagiri M, Oneyama T, Shimomura K, Sakurai S, Mataga I, Moride M and Hasegawa H: Experimental study of antiangiogenic gene therapy targeting VEGF in oral cancer. Odontology 98: 52-59, 2010.

28. Mishra S, Tang Y, Wang L, deGraffenried L, Yeh IT, Werner S, Troyer D, Copland JA and Sun LZ: Blockade of transforming growth factor-beta (TGF $\beta$ ) signaling inhibits osteoblastic tumorigenesis by a novel human prostate cancer cell line. Prostate 71 : 1441-1454, 2011

29. Papachristou DJ, Basdra EK and Papavassiliou AG: Bone metastases: Molecular mechanisms and novel therapeutic interventions. Med Res Rev 32: 611-636, 2012.

30. Kingsley LA, Fournier PG, Chirgwin JM and Guise TA: Molecular biology of bone metastasis. Mol Cancer Ther 6 : 2609-2617, 2007.

31. Hofbauer LC, Rachner TD, Coleman RE and Jakob F: Endocrine aspects of bone metastases. Lancet Diabetes Endocrinol 2: 500-512, 2014.

32. Mundy GR: Metastasis to bone: Causes, consequences and therapeutic opportunities. Nat Rev Cancer 2: 584-593, 2002.

33. Steeg PS: Tumor metastasis: Mechanistic insights and clinical challenges. Nat Med 12: 895-904, 2006.

34. Roodman GD: Biology of osteoclast activation in cancer. J Clin Oncol 19: 3562-3571, 2001.

35. Thomas RJ, Guise TA, Yin JJ, Elliott J, Horwood NJ, Martin TJ and Gillespie MT: Breast cancer cells interact with osteoblasts to support osteoclast formation. Endocrinology 140: 4451-4458, 1999.
36. Tulotta $\mathrm{C}$ and Ottewell P: The role of IL-1B in breast cancer bone metastasis. Endocr Relat Cancer 25: R421-R434, 2018.

37. Fili S, Karalaki M and Schaller B: Mechanism of bone metastasis: The role of osteoprotegerin and of the host-tissue microenvironment-related survival factors. Cancer Lett 283: 10-19, 2009.

38. Palmqvist P, Persson E, Conaway HH and Lerner UH: IL-6, leukemia inhibitory factor, and oncostatin $\mathrm{M}$ stimulate bone resorption and regulate the expression of receptor activator of NF-kappa B ligand, osteoprotegerin, and receptor activator of NF-kappa B in mouse calvariae. J Immunol 169: 3353-3362, 2002.

39. Sunyer T, Lewis J, Collin-Osdoby P and Osdoby P: Estrogen's bone-protective effects may involve differential IL-1 receptor regulation in human osteoclast-like cells. J Clin Invest 103: $1409-1418,1999$

40. Wu X, Zeng R, Wu S, Zhong J, Yang L and Xu J: Comprehensive expression analysis of miRNA in breast cancer at the miRNA and isomiR levels. Gene 557: 195-200, 2015.

41. Calin GA and Croce CM: MicroRNA-cancer connection: The beginning of a new tale. Cancer Res 66: 7390-7394, 2006.

42. Schwarzenbach H, Hoon DS and Pantel K: Cell-free nucleic acids as biomarkers in cancer patients. Nat Rev Cancer 11: 426-437, 2011.

43. Chen WS, Leung CM, Pan HW, Hu LY, Li SC, Ho MR and Tsai KW: Silencing of miR-1-1 and miR-133a-2 cluster expression by DNA hypermethylation in colorectal cancer. Oncol Rep 28: 1069-1076, 2012.

44. Shi W, Tang T, Li X, Deng S, Li R, Wang Y, Wang Y, Xia T, Zhang Y, Zen K, et al: Methylation-mediated silencing of miR-133a-3p promotes breast cancer cell migration and stemness via miR-133a-3p/MAML1/DNMT3A positive feedback loop. J Exp Clin Cancer Res 38: 429, 2019.

45. Fabris L, Berton S, Citron F, D'Andrea S, Segatto I, Nicoloso MS, Massarut S, Armenia J, Zafarana G, Rossi S, et al: Radiotherapy-induced miR-223 prevents relapse of breast cancer by targeting the EGF pathway. Oncogene 35: 4914-4926, 2016.

46. Wang X, Tong Z and Liu H: MiR-223-3p targeting epithelial cell transforming sequence 2 oncogene inhibits the activity, apoptosis, invasion and migration of MDA-MB-468 breast cancer cells. OncoTargets Ther 12: 7675-7684, 2019.

47. McGuire A, Brown JA and Kerin MJ: Metastatic breast cancer: The potential of miRNA for diagnosis and treatment monitoring. Cancer Metastasis Rev 34: 145-155, 2015.

48. Hamam R, Hamam D, Alsaleh KA, Kassem M, Zaher W, Alfayez M, Aldahmash A and Alajez NM: Circulating microRNAs in breast cancer: Novel diagnostic and prognostic biomarkers. Cell Death Dis 8: e3045, 2017.

49. Di Mauro V, Crasto S, Colombo FS, Di Pasquale E and Catalucci D: Wnt signalling mediates miR-133a nuclear re-localization for the transcriptional control of Dnmt $3 \mathrm{~b}$ in cardiac cells Sci Rep 9: 9320, 2019

50. Liu N, Bezprozvannaya S, Williams AH, Qi X, Richardson JA, Bassel-Duby $\mathrm{R}$ and Olson EN: microRNA-133a regulates cardiomyocyte proliferation and suppresses smooth muscle gene expression in the heart. Genes Dev 22: 3242-3254, 2008.

51. Roffel MP, Bracke KR, Heijink IH and Maes T: miR-223: A key regulator in the innate immune response in asthma and COPD. Front Med (Lausanne) 7: 196, 2020.

52. Ye D, Zhang T, Lou G and Liu Y: Role of miR-223 in the pathophysiology of liver diseases. Exp Mol Med 50: 1-12, 2018.

53. Wang M, Xia F, Wei Y and Wei X: Molecular mechanisms and clinical management of cancer bone metastasis. Bone Res 8: 30 , 2020.

54. Fares J, Fares MY, Khachfe HH, Salhab HA and Fares Y: Molecular principles of metastasis: A hallmark of cancer revisited. Signal Transduct Target Ther 5: 28, 2020.

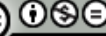

This work is licensed under a Creative Commons Attribution-NonCommercial-NoDerivatives 4.0 International (CC BY-NC-ND 4.0) License. 